\title{
AIDS-Related Burkitt Lymphoma with Plasmacytoid Differentiation
}

National Cancer Institute

\section{Source}

National Cancer Institute. AIDS-Related Burkitt Lymphoma with Plasmacytoid

Differentiation. NCI Thesaurus. Code C27857.

A Burkitt lymphoma with plasmacytoid differentiation occurring in HIV-positive patients. 